\title{
U so de bentonita na remediação de solos contaminados com zinco: Efeito na produção de feijão ${ }^{1}$
}

\author{
Gilvanise A. Tito ${ }^{2}$, Lucia H. G. Chaves ${ }^{3}$, Hugo 0. C. Guerra ${ }^{3} \&$ Frederico A. L. Soares ${ }^{4}$
}

\section{RESU MO}

Diversos procedimentos têm sido propostos para reduzir a concentração de metais pesados nos solos, e, conseqüentemente, seus efeitos poluidores. Dentre eles destacam-se a aplicação de materiais, como a bentonita, capazes de adsorver estes elementos, tornando-os menos disponíveis para as plantas. O bjetivouse com este trabalho avaliar a capacidade da bentonita na remediação de solos contaminados com zinco. Conduziu-se experimento em condições de casa de vegetação com delineamento inteiramente casualizado com três repetições e uma planta por parcela, utilizando-se como planta indicadora o feijão caupi (Vigna unguiculata L.). Os tratamentos consistiram de uma combinação fatorial $3 \times 3$, sendo o primeiro fator composto por três doses de $\mathrm{Zn}\left(50,250\right.$ e $\left.450 \mathrm{mg} \mathrm{kg}^{-1}\right)$ e o segundo fator por três doses de bentonita $(0,30$ e 60 t ha $^{-1}$ ). Para o estudo, utilizou-se vasos com capacidade de18 kg, preenchidos com $15 \mathrm{~kg}$ de solo em mistura com as respectivas doses de bentonita e com o zinco. O s tratamentos permaneceram incubados por um período de 10 dias, e em seguida foi realizada a semeadura da planta indicadora. Aos 65 dias após a semeadura colheram-se folhas, caules, raízes, sementes e casca, que, depois de secos em estufa de circulação de $\operatorname{ar}\left(65^{\circ} \mathrm{C}\right)$, foram pesados, moídos e analisados quanto aos teores de zinco. Os resultados evidenciaram que a bentonita parece ser um excelente material inorgânico para remediar solos contaminados com zinco. A incorporação de bentonita ao solo aumenta a adsorção do zinco diminuindo a disponibilidade deste elemento para a planta tendendo, consequentemente, aumentar a produção de massa seca.

Palavras-chave: metal pesado, argila, Vigna unguiculata L.

\section{Use of bentonite in the remediation of soils contaminated with zinc: Effect on bean production}

\section{A B STRACT}

Several procedures have been proposed to reduce the concentration of heavy metals in soils and consequently, to reduce polluting effects. O ne of the most used procedures is the application of materials such as bentonite capable of adsorbing these elements making them less available to plants. The objective of this study was to evaluate the ability of bentonite in the remediation of soils contaminated with zinc. An experiment was carried out in a greenhouse in a completely randomized design with three replications, using cowpea (Vigna unguiculata L.) as an indicator plant. Treatments consisted of a $3 \times 3$ factorial, the first factor being three doses of $\mathrm{Zn}\left(50,250\right.$ and $\left.450 \mathrm{mg} \mathrm{kg}^{-1}\right)$ and the second factor three doses of bentonite $\left(0,30\right.$ and $\left.60 \mathrm{tha}^{-1}\right)$. For the study pots with $18 \mathrm{~kg}$ filled with $15 \mathrm{~kg}$ of soil mixed with the respective doses of bentonite and zinc were used. After ten days of soil incubation the bean seeds were sown. After sixty five days leaves, stems, roots, seeds and bark were harvested separately, dried in air circulation oven at $65^{\circ} \mathrm{C}$, weighed, grinded and analyzed for zinc. The results show ed that the bentonite seems to be an optimum inorganic material for remediation of soils contaminated with zinc. The incorporation of bentonite to the soil increases the adsorption of zinc by decreasing the availability of this element for the plant tending therefore to increase the production of dry matter.

Key words: heavy metal, clay, Vigna unguiculata L.

${ }^{1}$ Parte da tese de doutorado da primeira autora, apresentada a U nidade Acadêmica da Engenharia Agrícola da U niversidade Federal de Campina Grande 2 Engenharia Agricola. UAEA/U FCG, Fone (83)2101-1285. E-mail: gilvanisetito@yahoo.com.br

${ }^{3}$ U AEA/U FCG , Av. A prígio Veloso, 882, Bodongó, CEP 58429-140, Campina G rande, PB. Fone: (83) 2101-1285. E-mail: Ihgarofalo@hotmail.com; hugo_carvallo@hotmail.com

4 Pós-doutorando, UAEA/U FCG. E-mail: fredalsoares@hotmail.com 


\section{INTRODUÇÃO}

A crescente atividade de mineração tem aumentado de forma alarmante a concentração de zinco no solo, principalmente em países industrializados, onde as indústrias destinam seus resíduos a soterramentos e sedimentação (Paim et al., 2006). De forma similar, o uso de fertilizantes minerais tradicionais ou de fontes alternativas, alguns pesticidas e corretivos utilizados para a melhoria das condições químicas e físicas do solo tem incorporado muito desse elemento ao solo contribuindo para a contaminação ambiental (Lima, 2001). Isto se torna mais preocupante quando se pensa na fertilização de plantas utilizadas diretamente na alimentação humana, como as hortaliças e os grãos (Alcarde \& Rodella, 2003).

A bentonita por ser um argilo-mineral composto predominantemente de esmectita, com alta capacidade de troca catiônica, de fácil obtenção e baixo custo, vem sendo avaliada como sorvente alternativo na remoção de metais de diversos ambientes (Mellah \& Chegrouche, 1997; Ayuso \& Sanchez, 2003; Lacin et al., 2005, Chaves \& Tito, 2011). De acordo com Kumpiene et al. (2008), a fração argila possui forte afinidade com metais pesados, havendo um aumento da adsorção destes com o aumento do teor de argila.

Solos com teores de zinco abaixo de 10 a $20 \mathrm{mg} \mathrm{kg}^{-1}$ são considerados deficientes, enquanto aqueles com níveis entre 25 a $150 \mathrm{mg} \mathrm{kg}^{-1}$ apresentam o metal em quantidades ideais à nutrição das plantas. Quando a concentração atinge patamares maiores que $400 \mathrm{mg} \mathrm{kg}^{-1}$, passa a ser considerado tóxico às plantas (Kabata-Pendias \& Pendias, 2001). A mobilidade desse elemento no solo depende, fundamentalmente, das reações químicas de adsorção e dessorção que ocorrem entre ele e os componentes sólidos do sistema. Essas reações são influenciadas por vários fatores, merecendo destaque a presença de ligantes orgânicos e inorgânicos, a presença de óxidos, os teores de carbono e do pH do solo (Kabata-Pendias \& Pendias, 2001; Fadigas et al., 2006; Clemente \& Bernal, 2006; Kidd et al., 2007; Bose \& Bhattacharyya, 2008).

A retenção do zinco no solo pode diminuir a sua biodisponibilidade no sistema solo-solução. Diversos materiais sorventes não convencionais, como por exemplo, a turfa e os minerais de argila, têm sido objeto de estudos e propostos para a remoção deste íon de soluções aquosas (Kalmykova et al., 2008; Leon et al., 2001). Principalmente estes minerais sendo, predominantemente, carregados negativamente, são considerados a parte ativa dos solos influenciando a retenção e movimentação de água no solo, a adsorção e troca catiônica, sendo esta última, o mecanismo mais importante para os poluentes inorgânicos, tais como os metais pesados (Fungaro et al., 2004).

Diante do exposto, objetivou-se com este trabalho avaliar o efeito da bentonita na adsorção de zinco em um solo contaminado e sua influência no desenvolvimento do feijão macassar (Vigna unguiculata (L.) Walp).

\section{Material e mÉtodos}

O experimento foi realizado em condições de casa de vegetação no Departamento de Engenharia Agrícola da
Universidade Federal de Campina Grande, município de Campina Grande, PB. O delineamento experimental utilizado foi inteiramente casualizado, com três repetições, em arranjo fatorial $3 \times 3$, sendo composto por três doses de bentonita $(0 ; 30$ e 60 $\mathrm{t} \mathrm{ha}^{-1}$ ) e três doses de zinco $\left(50,250\right.$ e $\left.450 \mathrm{mg} \mathrm{kg}^{-1}\right)$ totalizando 27 unidades experimentais. Cada unidade experimental constou de um vaso de plástico com $15 \mathrm{~kg}$ de solo, previamente seco ao ar, peneirado e misturado com as doses de bentonita correspondentes a cada tratamento. $\mathrm{O}$ material utilizado foi um solo classificado como Argissolo Acinzentado distrófico, de textura areia franca, coletado na camada de $0,20 \mathrm{~m}$ de profundidade, com as seguintes características químicas determinadas pelos métodos adotados pela EMBRAPA(1997): $\mathrm{pH}\left(\mathrm{H}_{2} \mathrm{O}\right)=5,8 ; \mathrm{Ca}=2,61 \mathrm{cmol}_{\mathrm{c}} \mathrm{kg}^{-1} ; \mathrm{Mg}=0,83 \mathrm{cmol}_{\mathrm{c}} \mathrm{kg}^{-1}$; $\mathrm{Na}=0,03 \mathrm{cmol}_{\mathrm{c}} \mathrm{kg}^{-1} ; \mathrm{K}=0,05 \mathrm{cmol} \mathrm{kg}^{-1} ; \mathrm{H}+\mathrm{Al}=1,48 \mathrm{cmol}_{\mathrm{c}}^{\mathrm{c}} \mathrm{kg}^{-1}$; $\mathrm{MO}=16,2 \mathrm{~g} \mathrm{~kg}^{-1} ; \mathrm{P}=18,3 \mathrm{mg} \mathrm{kg}^{-1}$. Após o preparo das misturas solo + bentonita, as mesmas foram fertilizadas de acordo com a recomendação de adubação para o feijoeiro e acondicionadas nos vasos. Em seguida, as misturas foram irrigadas com soluções contendo Zn, de acordo com os tratamentos, e água destilada para que as mesmas permanecessem com umidade correspondente a $80 \%$ da capacidade de campo. Visando dar oportunidade à bentonita de interagir com o solo e o metal adicionado, os vasos permaneceram incubados durante dez dias, mantendo-se a umidade do solo próxima a capacidade de campo. Transcorridos 10 dias do início da incubação foi realizada a semeadura diretamente nos vasos a $2 \mathrm{~cm}$ de profundidade. Em seguida iniciou-se a irrigação das mesmas com de água destilada, mantendo-se a umidade correspondente a $80 \%$ da capacidade de campo. Aos 20 dias após a semeadura foi feito o desbaste deixando uma planta por vaso. Ao final do experimento, por ocasião da colheita, 65 dias após a semeadura, as plantas foram colhidas, separadas em folhas, caules, raízes e sementes, secadas em estufa de circulação forçada de ar a $65^{\circ} \mathrm{C}$ até peso constante, pesadas e moídas. Posteriormente, as amostras vegetais foram submetidas a digestão nitroperclórica para determinação de Zn nos extratos através da espectrofotometria de absorção atômica, de acordo com metodologia proposta por Tedesco et al. (1995).

O acúmulo (A) do Zn nas folhas, caules, raízes e grãos das plantas ( $\mu \mathrm{g} /$ parte da planta) foi calculado pela expressão A (MSC, ou MSF ou MSR ou MSG (mg) x Concentração do elemento $\left.\left(\mathrm{mg} \mathrm{kg}^{-1}\right)\right)$ / 1000, onde MSC - massa seca dos caules; MSF - massa seca das folhas; MSR - massa seca das raízes; MSG - massa seca dos grãos. Por meio da quantidade total acumulada, calculou-se a porcentagem de acúmulo do metal para cada parte da planta. Através da análise de crescimento vegetativo e do teor de metal contido na planta calculou-se a eficiência de translocação (ET) dos elementos pela equação ET - conteúdo (mg) do metal na massa seca da parte aérea/ conteúdo (mg) de metal na massa seca total.

Os resultados foram submetidos à análise de variância, e análise de regressão polinomial, utilizando-se o programa SISVAR (Ferreira, 2003).

\section{RESULTADOS E DISCUSSÃO}

Conforme os resultados da análise de variância (Tabela 1), a produção de massa seca dos caules, grãos, casca e sobre a 
Tabela 1. Resumo da análise de variância para massa seca (MS) das folhas, caules, raízes, grãos, casca e total das plantas de feijão em função doses de bentonita (B) e doses de zinco (Zn)

\begin{tabular}{|c|c|c|c|c|c|c|c|}
\hline \multirow{2}{*}{ Fonte de variação } & \multirow{2}{*}{ GL } & \multicolumn{6}{|c|}{ Quadrado médio } \\
\hline & & Folha & Caule & Raiz & Grão & Casca & $\mathbf{T}$ \\
\hline $\mathrm{Zn}$ & 2 & $5,05 \mathrm{~ns}$ & $46,82 *$ & $0,10 \mathrm{~ns}$ & $22,85 *$ & $4,78 *$ & $259,15^{*}$ \\
\hline$B$ & 2 & 1,06 ns & 3,07 ns & 0,27 ns & $0,06 \mathrm{~ns}$ & $1,44 *$ & $5,85 \mathrm{~ns}$ \\
\hline$Z n \times B$ & 4 & $2,84 \mathrm{~ns}$ & $2,57 \mathrm{~ns}$ & $0,10 \mathrm{~ns}$ & $1,50 \mathrm{~ns}$ & $1,81 *$ & $22,45 \mathrm{~ns}$ \\
\hline Resíduo & 18 & 2,40 & 1,57 & 0,45 & 0,79 & 0,15 & 11,20 \\
\hline \multirow[t]{2}{*}{ CV } & & 17,47 & 15,11 & 24,19 & 8,96 & 21,10 & 10,57 \\
\hline & & \multicolumn{6}{|c|}{ Média - g vaso-1 } \\
\hline \multicolumn{8}{|l|}{$\mathrm{Zn}$} \\
\hline $50 \mathrm{mg} \mathrm{kg}^{-1}$ & & $9,43 a$ & $10,48 a$ & $2,88 a$ & $11,55 a$ & $2,66 a$ & 36,99 a \\
\hline $250 \mathrm{mg} \mathrm{kg}^{-1}$ & & 9,16 a & $8,49 \mathrm{~b}$ & $2,74 a$ & $9,78 \mathrm{~b}$ & $1,58 \mathrm{~b}$ & $31,75 \mathrm{~b}$ \\
\hline \multicolumn{7}{|l|}{ B } & $26,26 \mathrm{c}$ \\
\hline 0 tha $^{-1}$ & & 9,14 a & $7,66 \mathrm{a}$ & $2,94 \mathrm{a}$ & $9,81 \mathrm{a}$ & $1,58 \mathrm{~b}$ & 31,12 a \\
\hline 30 tha $^{-1}$ & & $8,48 \mathrm{a}$ & $8,44 a$ & $2,76 a$ & $9,96 \mathrm{a}$ & $1,63 \mathrm{~b}$ & $31,28 \mathrm{a}$ \\
\hline 60 tha $^{-1}$ & & 8,98 a & 8,80 a & $2,59 a$ & 9,93 a & $2,30 a$ & $32,59 a$ \\
\hline
\end{tabular}

* Significativo no nível de 5\% pelo Teste Tukey; ns - não significativo

massa seca total responderam à aplicação de Zn corroborando com Muner et al. (2011) e discordando com Santos et al. (2009a). As doses de bentonita e a interação entre elas e as doses de Zn, só apresentaram efeito significativo para a variável produção de massa seca da casca.

Em geral, as produções de massa seca de todas as partes das plantas diminuíram em função do aumento das doses de Zn aplicadas. A redução de aproximadamente, $31 \%$ na produção de massa seca da parte aérea (MSPA), variou de 34,11 a 23,59 $\mathrm{g}$, valores estes obtidos nos tratamentos contendo 50 e $450 \mathrm{mg}$ $\mathrm{kg}^{-1}$ de $\mathrm{Zn}$ no solo, respectivamente. Essa redução é semelhante aos $29 \%$ constatados por Carvalho et al. (2008) ao estudar os efeitos de doses crescentes deste mesmo elemento (de 0 a 54 $\mathrm{mg} \mathrm{dm}^{-3}$ ) em Phaseolus vulgaris L.. A redução na MSPA também foi observada por Marsola et al. (2005), tendo o feijoeiro como planta indicadora.

A produção de grãos diminuiu em função das doses crescentes de $\mathrm{Zn}$, contrariando o que foi observado por Carvalho et al. (2008). Segundo Malavolta et al. (1997), uma das razões para esta diminuição é que o zinco acumula-se em tampões ("plugs") no xilema dificultando a ascensão da seiva bruta e consequentemente, o aproveitamento do elemento para o desenvolvimento das plantas.

A representação gráfica das regressões obtidas para a produção da massa seca dos caules, grãos e total em função das doses de zinco pode ser visualizada na Figura 1 (A, B e C) sendo nas equações refletindo o comportamento linear para todas estas variáveis, diminuindo as produções com o aumento das doses de zinco.

Mesmo não tendo efeito significativo das doses de bentonita sobre a produção de massa seca das diferentes partes das plantas, com exceção da casca, pode-se observar, em geral, uma tendência de aumento na massa seca à medida que se aumentaram as doses de bentonita, evidenciando o efeito benéfico da bentonita (Tabela 1).

Analisando o desdobramento para a produção de massa seca da casca (Tabela 2), pode-se observar que houve diferença significativa entre as doses de zinco aplicadas em solos, contendo a dose de $60 \mathrm{t} \mathrm{ha}^{-1}$ (B60) de bentonita, apresentando uma diminuição da massa seca em função do aumento das
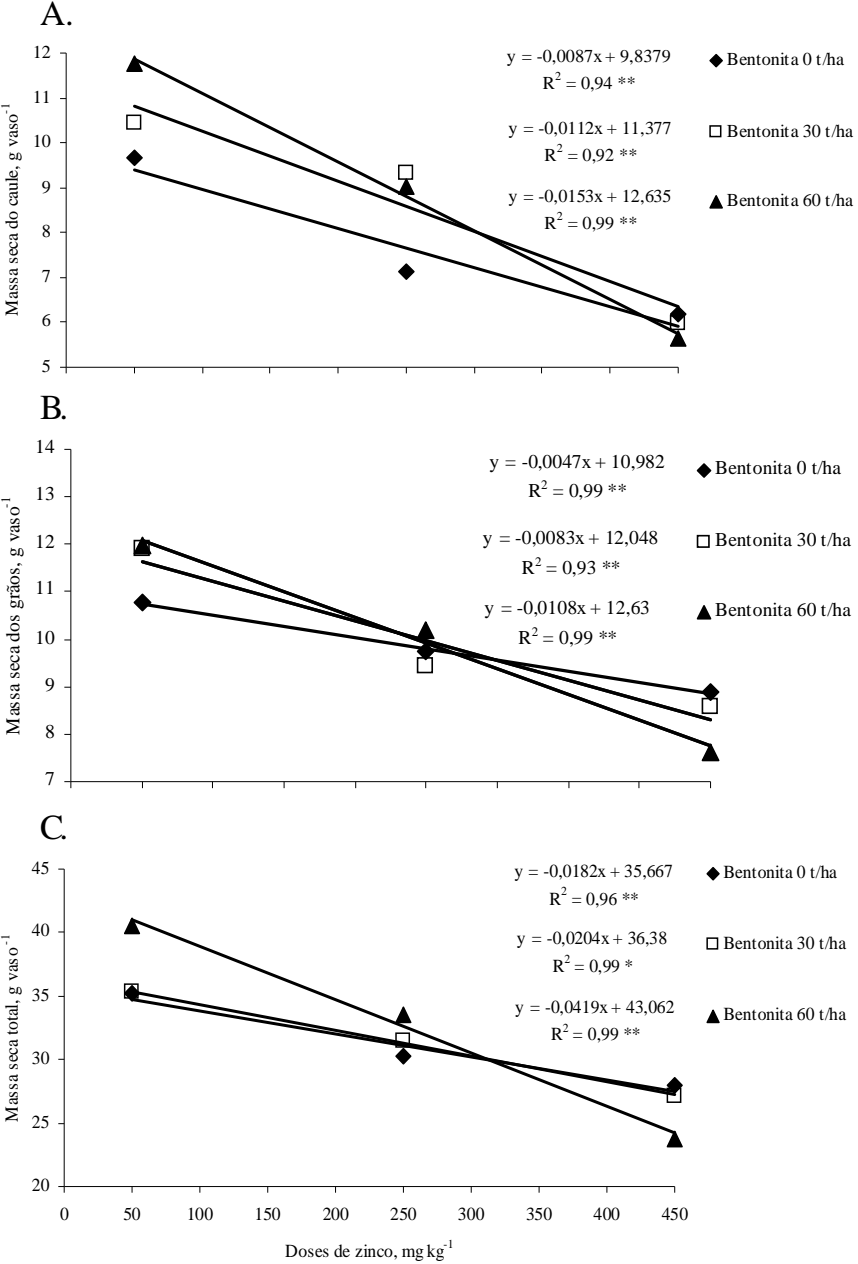

Figura 1. Massa seca dos caules, grãos e total das plantas de feijoeiro em função de doses de zinco $(Z n)$

doses de zinco. Por outro lado, ao estudar a influência das doses de bentonita, observou-se diferença significativa da produção de massa seca da casca das plantas cultivadas apenas com a dose de $50 \mathrm{mg} \mathrm{kg}^{-1}$ de $\mathrm{Zn}$ aplicada.

As equações das representações gráficas das regressões (Figura 2A e B) refletem a resposta linear para massa seca das 
Tabela 2. Desdobramento da produção de massa seca (MS) da casca de plantas de feijão em função de doses de zinco $\left(50,250\right.$ e $\left.450 \mathrm{mg} \mathrm{kg}^{-1}\right)$ e doses de bentonita $(0,30$ e 60 t ha-1) $^{-1}$

\begin{tabular}{|c|c|c|c|c|}
\hline \multirow{2}{*}{$\begin{array}{c}\text { Doses de bentonita } \\
\text { t ha }\end{array}$} & \multicolumn{3}{|c|}{ Doses de zinco, $\mathrm{mg} \mathrm{kg}^{-1}$} & \multirow{2}{*}{ Média } \\
\hline & 50 & 250 & 450 & \\
\hline $\begin{array}{c}0 \\
30 \\
60 \\
\text { Média Zn }\end{array}$ & $\begin{array}{l}1,91 \text { b A } \\
1,91 \text { b A } \\
4,15 \text { a A } \\
2,66 \mathrm{~A}\end{array}$ & $\begin{array}{l}1,56 \text { a } A \\
1,66 \text { a } A \\
1,51 \text { a } B \\
1,58 \text { B }\end{array}$ & $\begin{array}{l}1,26 \text { a } A \\
1,32 \text { a A } \\
1,23 \text { a B } \\
1,27 \text { B }\end{array}$ & $\begin{array}{l}1,58 \mathrm{~b} \\
1,63 \mathrm{~b} \\
2,30 \mathrm{a}\end{array}$ \\
\hline
\end{tabular}

Letras maiúsculas iguais não diferem na horizontal e letras minúsculas iguais não diferem na vertical

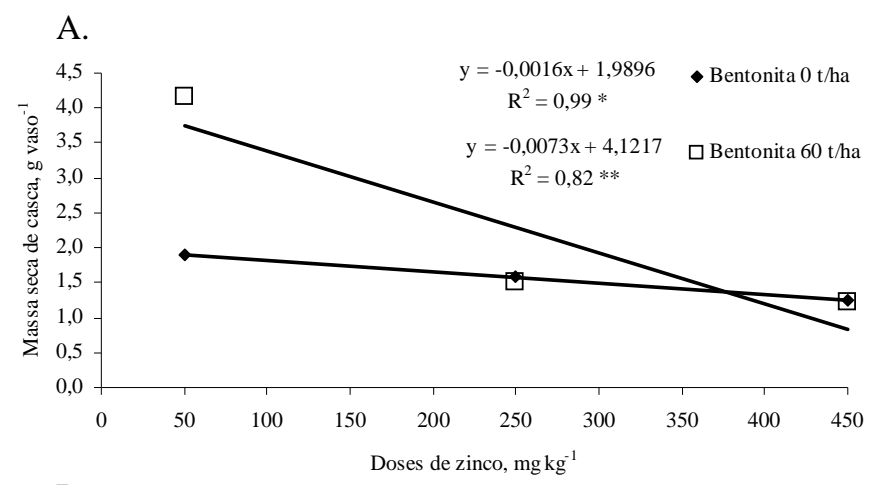

$$
\text { B. }
$$

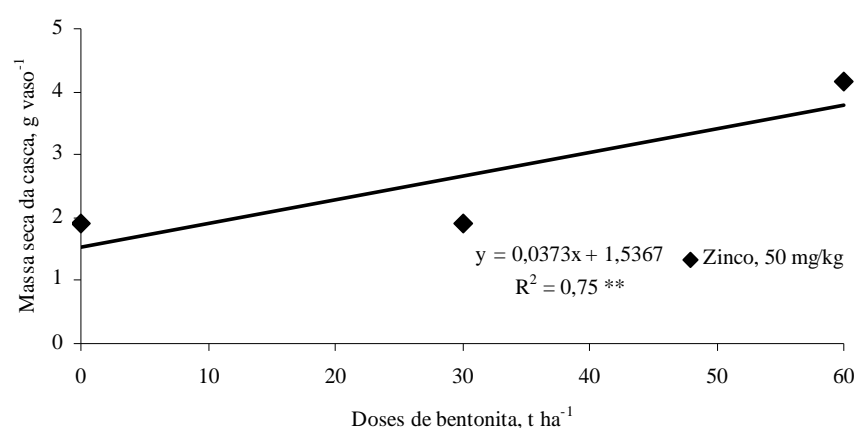

Figura 2. M assa seca das cascas das plantas de feijoeiro em função das doses de zinco (Zn) (A) e doses de bentonita (B)

cascas em função das doses de zinco e doses de bentonita. Observa-se que a massa seca das cascas diminuiu em função do aumento das doses de zinco tanto das unidades experimentais que não receberam bentonita como naquelas com a maior dose de bentonita. Por outro lado, a produção da massa seca das cascas aumentou em função das doses de bentonita nas unidades experimentais que receberam somente a dose de $50 \mathrm{mg} \mathrm{kg}^{-1}$ de zinco.

As doses de $\mathrm{Zn}$ utilizadas promoveram efeito significativo sobre a concentração do elemento nas folhas, caules, raiz, grãos e casca. As doses de bentonita (B) só influenciaram significativamente sobre a concentração do zinco no caule e no grão. Entretanto, as doses 0 e $30 \mathrm{t} \mathrm{ha}^{-1}$, e 30 e $60 \mathrm{t} \mathrm{ha}^{-1}$ não diferiram estatisticamente entre si. A interação entre as doses de bentonita e de $\mathrm{Zn}$ aplicadas no solo não promoveram efeito significativo sobre a concentração do metal em todas as partes da planta (Tabela 3).

$\mathrm{A}$ adição de $\mathrm{Zn}$ ao substrato aumentou a concentração do nutriente nas diferentes partes da planta, no entanto, não promoveu acréscimo sobre a produção de massa seca das mesmas, como foi constatado na Tabela 1. Isto evidencia que as plantas têm capacidade de absorver e acumular quantidades bem maiores do que elas precisam para realizar seus processos metabólicos. Tal fato pode ser observado em outras culturas pelas quais aumenta a absorção de $\mathrm{Zn}$ em função das doses do elemento aplicadas ao solo (Pereira et al., 2007; Natale et al., 2002; Muner et al., 2011).

As concentrações observadas em todas as partes das plantas (Tabela 3), com exceção dos grãos e da casca, na dose de $50 \mathrm{mg} \mathrm{kg}^{-1}$, ultrapassaram os valores normais previstos para o feijoeiro, que variam entre $30 \mathrm{e} 100 \mathrm{mg} \mathrm{kg}^{-1}$. Kabata-Pendias \& Pendias (2001) sugerem valores entre 100 e $400 \mathrm{mg} \mathrm{kg}^{-1}$ como adequados, enquanto Bergmann (1992), mencionam a faixa de 300 a $500 \mathrm{mg} \mathrm{kg}^{-1}$ como tóxicas. Constata-se então, que nas folhas, caules e raízes das plantas que receberam 250 e 450 $\mathrm{mg} \mathrm{kg}^{-1}$ de $\mathrm{Zn}$, as concentrações estavam muito altas, acima dos teores sugeridos pelos autores acima citados.

Comparando as concentrações de $\mathrm{Zn}$ nas diferentes partes das plantas submetidas às doses crescentes de bentonita, pode-se observar que os maiores valores ocorreram nas raízes. Este resultados corroboram com Marsola et al. (2005), Mesquita et al. (2006), e Carvalho et al. (2008). Embora o Zn seja móvel

Tabela 3. Resumo da análise de variância da concentração do zinco nas folhas, caules, raízes, grãose casca das plantas de feijão em função das doses crescentes de bentonita (B) e zinco (Zn)

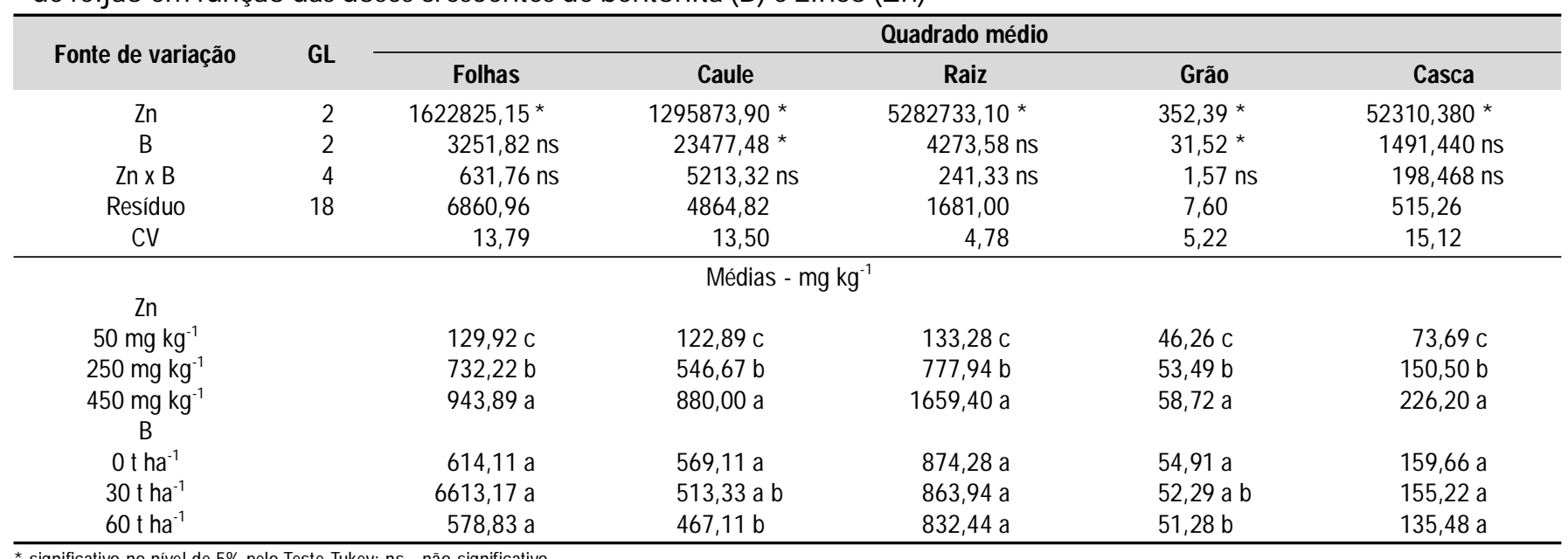

* significativo no nível de $5 \%$ pelo Teste Tukey; ns - não significativo 
dentro da planta, a raiz atua como "barreira" deste elemento, diminuindo a possibilidade de toxidez da planta, corroborando com Oliveira et al. (2005). A maior concentração de Zn nas raízes pode ter provocado a menor produção de massa seca em comparação com a observada para caules e folhas (Tabela 1). Neste contexto parece que as raízes são mais sensíveis ao zinco (Barceló \& Poschenrieder, 1992), o que pode ser um indicativo de que a planta limitou a translocação do metal das raízes para a parte aérea.

$\mathrm{Na}$ medida em que a quantidade de bentonita aplicada ao solo aumentou, as concentrações de $\mathrm{Zn}$ nas diferentes partes das plantas diminuíram indicando uma possível diminuição na disponibilidade do elemento no solo, decorrente de sua adsorção pela bentonita (Tabela 3). Mesmo para a folha, raiz e casca que não apresentou efeito significativo pode-se observar uma tendência de redução da concentração nestas partes da planta.

A eficiência de translocação (ET) foi influenciada de forma significativa pelas doses de $\mathrm{Zn}$ utilizadas tendo diminuído em função do aumento das mesmas (Tabela 4).

Tabela 4. Resumo da análise de variância para a eficiência de translocação do zinco, submetidas aos tratamentos, doses de zinco (Zn) e doses de bentonita (B)

\begin{tabular}{ccc}
\hline Fonte de variação & GL & Quadrado médio \\
Zn & 2 & $0,0439 *$ \\
B & 2 & $0,0006 \mathrm{~ns}$ \\
Zn x B & 4 & $0,0005 \mathrm{~ns}$ \\
Resíduo & 18 & 0,0009 \\
CV & & 3,71 \\
\hline Zn & Médias \\
$50 \mathrm{mg} \mathrm{kg}^{-1}$ & mg mg \\
$250 \mathrm{mg} \mathrm{kg}^{-1}$ & $0,89 \mathrm{a}$ \\
$450 \mathrm{mg} \mathrm{kg}^{-1}$ & $0,85 \mathrm{~b}$ \\
$\mathrm{~B}$ & $0,75 \mathrm{c}$ \\
$0 \mathrm{t} \mathrm{ha}^{-1}$ & \\
$30 \mathrm{t} \mathrm{ha}^{-1}$ & & $0,82 \mathrm{a}$ \\
$60 \mathrm{tha}^{-1}$ & & $0,83 \mathrm{a}$ \\
\hline
\end{tabular}

* significativo no nível de 5\% pelo Teste Tukey; ns - não significativo
Doses excessivas de $\mathrm{Zn}$ prejudicam mais os processos de translocação que os de absorção. Segundo Natale et al. (2002) a redução de translocação do $\mathrm{Zn}$ pode ser explicado pelo mecanismo das plantas em aumentar a tolerância à toxidez de zinco, pois, nestas condições, tem-se maior acúmulo do elemento nos vacúolos das células do córtex da raiz. Resultados semelhantes na queda do ET de $\mathrm{Zn}$, com doses excessivas do metal, foram observados em mudas de goiabeira (Natale et al., 2002). Mesmo assim, os valores da ET foram elevados indicando a alta capacidade do Zn de translocar-se das raízes para a parte aérea do feijoeiro.

Com exceção dos grãos, os teores de Zn influenciaram de forma significativa o acúmulo do elemento na planta discordando de Santos et al. (2009b) que observaram que o Zn influenciou no acúmulo do elemento nos grãos. Por outro lado, as doses de bentonita não tiveram efeito significativo e a interação dos tratamentos influenciou apenas no acúmulo do $\mathrm{Zn}$ na casca dos grãos de feijoeiro (Tabela 5).

$\mathrm{O}$ acúmulo de Zn na massa seca das diferentes partes da planta, com exceção dos grãos, aumentou com a elevação das doses do elemento (Tabela 5), concordando com os resultados obtidos por Natale et al. (2002). Observa-se que com a aplicação da menor dose de Zn a maior acumulação do elemento foi encontrada no caule. Já com a aplicação das duas maiores doses do elemento às unidades experimentais, o maior acúmulo do mesmo foi encontrado nas folhas das plantas confirmando os dados de Oliveira et al. (2005).

$\mathrm{O}$ aumento do acúmulo de $\mathrm{Zn}$ foi considerável com a aplicação de $250 \mathrm{mg} \mathrm{kg}^{-1}$ de Zn em relação à dose de $50 \mathrm{mg} \mathrm{kg}^{-1}$, correspondendo a 466,29; 257,30; 450,71 e 25,17\% nas folhas, caule, raiz e casca, respectivamente. Já em relação à dose 450 mg kg-1 o aumento foi menos acentuado correspondendo a 11,$21 ; 13,49 ; 108,47$ e 19,71\% nas folhas, caule, raiz e casca, respectivamente. No caso do acréscimo das doses de bentonita, mesmo não apresentando efeito significativo, pode-se dizer que, com exceção da casca, houve uma tendência de diminuição do acúmulo do metal nas demais partes da planta.

A quantidade de $\mathrm{Zn}$ acumulada nas plantas é provavelmente uma consequência da concentração do elemento no tecido

Tabela 5. Resumo da análise de variância para acúmulo do zinco nas folhas, caules, raízes, grãos e casca de plantas de feijoeiro em função de doses de zinco (Zn) e doses de bentonita (B)

\begin{tabular}{|c|c|c|c|c|c|c|}
\hline \multirow{2}{*}{ Fonte de variação } & \multirow{2}{*}{ GL } & \multicolumn{5}{|c|}{ Quadrado médio } \\
\hline & & Folha & Caule & Raiz & Grão & Casca \\
\hline $\mathrm{Zn}$ & 2 & $104674222,00 *$ & $39587925,50 *$ & $37322065,70 *$ & $4092,29 \mathrm{~ns}$ & $20311,80 *$ \\
\hline$B$ & 2 & $979299,20 \mathrm{~ns}$ & 743286,20 ns & $436627,20 \mathrm{~ns}$ & $2587,24 \mathrm{~ns}$ & $193,57 \mathrm{~ns}$ \\
\hline $\mathrm{Zn} \times \mathrm{B}$ & 4 & $1057175,70 \mathrm{~ns}$ & $374521,00 \mathrm{~ns}$ & 234330,00 ns & $4558,17 \mathrm{~ns}$ & $12324,60 *$ \\
\hline Resíduo & 18 & 1038969,70 & 556192,90 & 1025176,90 & 2777,81 & 3672,33 \\
\hline \multirow[t]{2}{*}{$\mathrm{CV}$} & & 20,01 & 20,31 & 43,60 & 10,21 & 25,43 \\
\hline & & \multicolumn{5}{|c|}{ Médias - $\mu \mathrm{g}$ planta $^{-1}$} \\
\hline \multicolumn{7}{|c|}{ 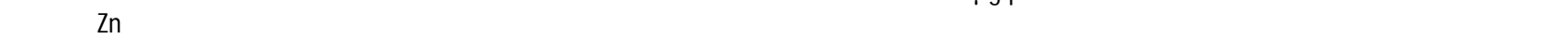 } \\
\hline $50 \mathrm{mg} \mathrm{kg}^{-1}$ & & $1178,89 \mathrm{~b}$ & $1276,92 \mathrm{~b}$ & $387,33 c$ & $533,33 a$ & $190,63 b$ \\
\hline $250 \mathrm{mg} \mathrm{kg}^{-1}$ & & $6675,98 a$ & $4562,42 \mathrm{a}$ & $2133,08 b$ & $523,09 a$ & $238,61 a b$ \\
\hline \multicolumn{7}{|l|}{ B } \\
\hline 0 t ha $^{-1}$ & & $5466,30 \mathrm{a}$ & $3884,88 a$ & $2516,68 a$ & $534,60 a$ & $234,48 a$ \\
\hline 30 t ha $^{-1}$ & & $4972,18 \mathrm{a}$ & $3787,01 \mathrm{a}$ & $2367,50 a$ & $513,01 \mathrm{a}$ & $236,94 a$ \\
\hline 60 tha $^{-1}$ & & $4840,67 a$ & $3345,46 a$ & $2083,13 a$ & $501,16 a$ & $243,46 a$ \\
\hline
\end{tabular}

* significativo no nível de 5\% pelo Teste Tukey; ns - não significativo 
vegetal, uma vez que a adição do elemento não aumentou a massa seca das plantas, corroborando com Pereira et al. (2007).

As equações das regressões refletem de forma linear tanto a concentração como o acúmulo de zinco em folhas, nos caules, nas raízes e nas cascas (Figuras 3A, B, C e 4), ou seja, este
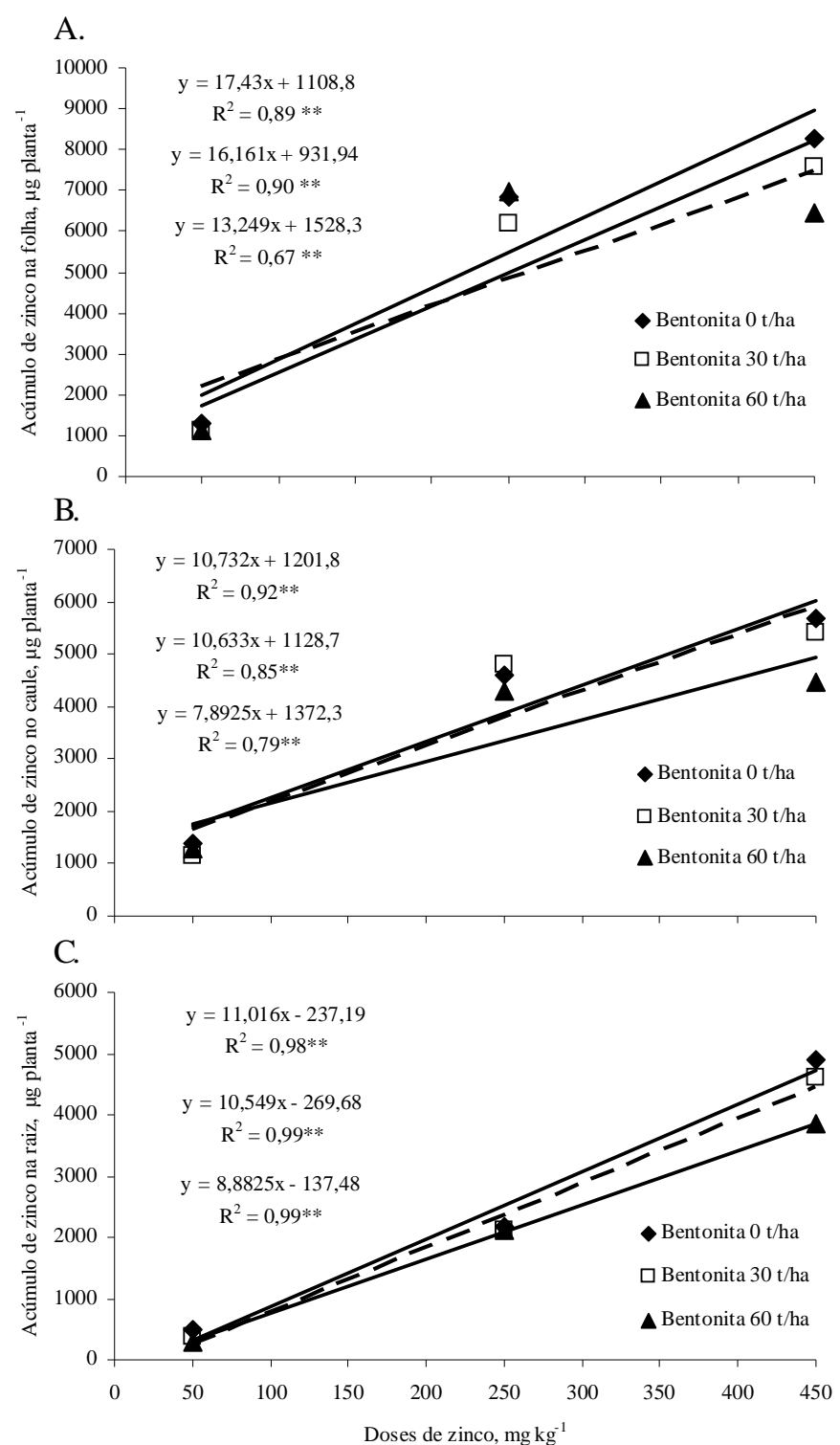

Figura 3. Acúmulo de zinco nas folhas, caules e raízes das plantas de feijoeiro em função doses de zinco (Zn)

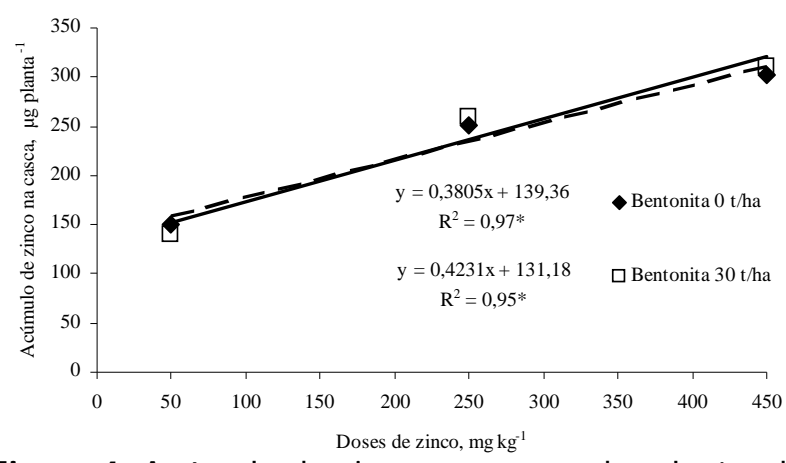

Figura 4. Acúmulo de zinco nas cascas das plantas de feijão em função doses de zinco (Zn) acúmulo nas partes das plantas aumentou em função do aumento das doses de zinco aplicadas, independente da quantidade de bentonita associada aos tratamentos.

Ao analisar o desdobramento da variável casca (Tabela 6), pode-se verificar que o aumento do acúmulo de $\mathrm{Zn}$ foi significativo com exceção da dose de $60 \mathrm{t} \mathrm{ha}^{-1}$ (B60). Já em relação às doses de bentonita, só houve diferença significativa do acúmulo do $\mathrm{Zn}$ na casca das plantas cultivadas com a dose de $50 \mathrm{mg} \mathrm{kg}^{-1}$ de $\mathrm{Zn}$.

Tabela 6. D esdobramento do acúmulo do zinco na casca das plantas de feijoeiro em função de doses de zinco (50, 250 e $\left.450 \mathrm{mg} \mathrm{kg}^{-1}\right)$ e doses de bentonita $\left(0,30\right.$ e 60 t ha $\left.^{-1}\right)$

\begin{tabular}{|c|c|c|c|c|}
\hline \multirow{2}{*}{$\begin{array}{c}\text { Doses de bentonita } \\
t_{\mathrm{tha}^{-1}}\end{array}$} & \multicolumn{3}{|c|}{ Doses de zinco, $\mathrm{mg} \mathrm{kg}^{-1}$} & \multirow{2}{*}{ Média DB } \\
\hline & 50 & 250 & 450 & \\
\hline 0 & $150,39 \mathrm{~b} \mathrm{~B}$ & 250,47 a $A B$ & 302,59 a A & $234,48 \mathrm{a}$ \\
\hline 30 & 140,66 b B & 260,28 a $A B$ & 309,88 a $A$ & $236,94 \mathrm{a}$ \\
\hline 60 & 280,85 a $A$ & 205,07 a A & 244,45 a $A$ & $243,46 a$ \\
\hline Média Zn & $190,63 \mathrm{~B}$ & $238,61 \mathrm{Ab}$ & $285,64 \mathrm{~A}$ & \\
\hline
\end{tabular}

Letras maiúsculas iguais não diferem na horizontal e letras minúsculas iguais não diferem na vertical

\section{CONCLUSÕES}

1. A presença de altas concentrações de zinco no solo diminuiu a produção de massa seca do feijoeiro.

2. A incorporação de bentonita no solo promoveu uma diminuição das concentrações de zinco nas diferentes partes da planta indicando uma possível diminuição na disponibilidade do elemento no solo, decorrente de sua adsorção pela bentonita.

3. A diminuição da disponibilidade de zinco para as plantas em solos contaminados promoveu uma tendência a aumentar a produção de massa seca da planta.

\section{Agradecimentos}

Agradecimentos especiais ao $\mathrm{CNPq}$, pela concessão de bolsas de doutorado à primeira autora e a Bentonit União Indústria e Comércio Ltda. pela doação da bentonita para a pesquisa.

\section{LITERATURA CITADA}

Alcarde, J. C.; Rodella, A. A. Qualidade e legislação de fertilizantes e corretivos. In: Curi, N.; Marques, J. J.; Guilherme, L. R. G.; Lima, J. M.; Lopes, A. S.; Alvarez, V. V. H. (ed). Tópicos em ciência do solo. Viçosa: Sociedade Brasileira de Ciência do Solo, 2003. cap.3, p.291-334.

Ayuso, E. A.; Sánchez, A. G. Removal of heavy metals from waste waters by natural and na-exchanged bentonites. Clays and Clay Minerals, v.51, p.475-480, 2003.

Barceló, J.; Poschenrieder, C. H. Respuestas de lãs plantas a la contaminacion por metales pesados. Suelo Planta, v.2, p.345361, 1992.

Bergmann, W. Nutrition disorders of plants-development, visual and analytical diagnosis. Stuttgart: Gustaf Fisher Verlag Jena, 1992. 741p.

Bose, S.; Bhattacharyya, A. K. Heavy metal accumulation in wheat plant grown in soil amended with industrial sludge. Chemosphere, v.70, p.1264-1272, 2008. 
Carvalho, A. V. S.; Carvalho, R.; Abreu, C. M. P.; Furtini Neto, A. E. Produção de matéria seca e de grãos por plantas de feijoeiro (Phaseolus vulgaris L.) cultivadas em solos tratados com metais pesados. Química Nova, v.31, p.949-955, 2008.

Chaves, L. H. G.; Tito, G. A. Cadmium and copper adsorption on bentonite: effects of $\mathrm{pH}$ and particle size. Revista Ciência Agronômica, v.42, p.278-284, 2011.

Clemente, R.; Bernal, M.P. Fractionation of heavy metals and distribution of organic carbon in two contaminated soils amended with humic acids. Chemosphere, v.64, p.1264-1273, 2006.

EMBRAPA- Empresa Brasileira de Pesquisa Agropecuária. Centro Nacional de Pesquisa de Solos. Manual de métodos de análise de solo. 2.ed. Rio de Janeiro: EMBRAPA, 1997. 212p.

Fadigas; F. S.; Amaral Sobrinho, N. M. B.; Mazur, N.; Anjos, L. H. C.; Freixo, A. A. Proposição de valores de referência para a concentração natural de metais pesados em solos brasileiros. Revista Brasileira de Engenharia Agrícola e Ambiental, v.10, p.699-705, 2006.

Ferreira, D. F. Sistema de análises estatísticas - SISVAR. Versão 4.6 (Build 60). DEX/ UFLA, 2003.

Fungaro, D. A.; Flues, M. S. M.; Celebroni, A. P. Estabilização de solo contaminado com zinco usando zeólitas sintetizadas a partir de cinzas de carvão. Química Nova, v.27, p.582-585, 2004.

Kabata-Pendias, A.; Pendias, H. Trace elements in soils and plants. 3.ed., Flórida: Boca Raton, 2001. 413p.

Kalmykova, Y.; Stromvall, A. M.; Steenari, B. M. Alternative materials for adsorption of heavy metals and petroleum hydrocarbons from contaminated leachates. Environmental Technology, v.29, p.111-122, 2008.

Kidd, P. S; Dominguez-Rodriguez, M. J.; Diez, J.; Monterroso, C. Bioavailability and plant accumulation of heavy metals and phosphorus in agricultural soils amended by long-term application of sewage sludge. Chemosphere, v.66, p.14581467, 2007.

Kumpiene, J.; Lagerkvist, A.; Maurice, C. Stabilization of As, $\mathrm{Cr}, \mathrm{Cu}, \mathrm{Pb}$ and $\mathrm{Zn}$ in soil using amendments $-\mathrm{A}$ review. Waste Management, v.28, p.215-225, 2008.

Lacin, O.; Bayrak, B.; Korkut, O.; Sayan, E. Modeling of adsorption and ultrasonic desorption of cadmium (II) and zinc (II) on local bentonite. Journal of Colloid and Interface Science, v.292, p.330-335, 2005.

Leon, A. T. de; Nunes, D. G.; Rubio, J. Remoção de íons de metais pesados com bentonitas modificadas. In: SHMMT, 6 e ENTMME, 18, 2001, Rio de Janeiro. Anais... Rio de Janeiro, 2001, p.464-470.

Lima, G. J. E. O. Biodisponibilidade de cádmio, zinco e chumbo presentes em calcário comercial para o feijoeiro cultivado em três solos de Minas do Noroeste de Minas Gerais. Lavras: UFLA, 2001. 148p. Dissertação Mestrado
Malavolta, E.; Vitti, G. C.; Oliveira, S. A. Avaliação do estado nutricional das plantas: Princípios e aplicações. Piracicaba: Potafos, 1997. 319p.

Marsola, T.; Miyazawa, M.; Pavan, M. A. Acumulação de cobre e zinco em tecidos do feijoeiro em relação com o extraído do solo. Revista Brasileira Engenharia Agrícola Ambiental, v.9, p.92-98, 2005.

Mellah, A.; Chegrouche, S. The removal of zinc from aqueous solutions by natural bentonite. Water Research, v.31, p.621629, 1997.

Mesquita, A. A.; Amaral Sobrinho, N. M. B.; Oliveira, C.: Mazur, N.; Santos, F. S. Remediação de solos tratados com lodo rico em zinco. Revista Brasileira de Engenharia Agrícola e Ambiental, v.10, p.738-744, 2006.

Muner, L. H. de; Ruiz, H. A.; Venegas, V. H. A.; Neves, J. C. L.; Freire, F. J.; Freire, M. B. G. dos S. Disponibilidade de zinco para milho em resposta à localização de fósforo no solo. Revista Brasileira de Engenharia Agrícola e Ambiental, v.15, p. 29-38, 2011.

Natale, W.; Prado, R. M.; Corrêa, M. C. M.; Silva, M. A. C.; Pereira, L. Resposta de mudas de goiabeira à aplicação de zinco. Revista Brasileira de Fruticultura, v.24, p.770-773, 2002.

Oliveira, C.; Amaral Sobrinho, N. M. B.; Marques, V. S.; Mazur, N. Efeito da aplicação do lodo de esgoto enriquecido com cádmio e zinco na cultura do arroz. Revista Brasileira de Ciência do Solo, v.28, p.109-116, 2005.

Paim, L. A.; Carvalho, R.; Abreu, C. M. P.; Guerreiro, M. C. Estudo dos efeitos do silício e do fósforo na redução da disponibilidade de metais pesados em área de mineração. Química Nova, v.29, p.28-33, 2006.

Pereira, N. M. Z.; Ernani, P. R.; Sangoi, L. Disponibilidade de zinco para o milho afetada pela adição de $\mathrm{Zn}$ e pelo $\mathrm{pH}$ do solo. Revista Brasileira de Milho e Sorgo, v.6, p.273-284, 2007.

Santos, H. C.; Fraga, V. S.; Raposo, R. W. C.; Pereira, W. E. Cu e Zn na cultura do sorgo cultivado em três classes de solos. I. Crescimento vegetativo e produção. Revista Brasileira de Engenharia Agrícola e Ambiental, v.13, p.125130, 2009a.

Santos, H. C.; Fraga, V. S.; Raposo, R. W. C.; Pereira, W. E. Cu e Zn na cultura do sorgo cultivado em três classes de solos. II. Composição mineral. Revista Brasileira de Engenharia Agrícola e Ambiental, v.13, p.131-136, 2009b.

Tedesco, M. J.; Gianello, C.; Bissani, C. A.; Bohnen, H.; Volkweiss. S. J. Análise de solo, plantas e outros materiais. 2.ed. Porto Alegre: Universidade Federal do Rio Grande do Sul, 1995. 174p. 